\title{
Wolves (Canis lupus) and Dogs (Canis familiaris) Differ in Following Human Gaze Into Distant Space But Respond Similar to Their Packmates' Gaze
}

\author{
Geraldine Werhahn \\ Wolf Science Center, Ernstbrunn, Austria and University \\ of Oxford \\ Gabriela Barrera \\ Wolf Science Center, Ernstbrunn, Austria and Research Institute \\ of Veterinary Science (ICiVet - Litoral) - UNL - CONICET
}

\author{
Zsófia Virányi \\ Wolf Science Center, Ernstbrunn, Austria and University
} of Vienna

\author{
Andrea Sommese \\ Wolf Science Center, Ernstbrunn, Austria
}

Friederike Range

Wolf Science Center, Ernstbrunn, Austria and University of Vienna

\begin{abstract}
Gaze following into distant space is defined as visual co-orientation with another individual's head direction allowing the gaze follower to gain information on its environment. Human and nonhuman animals share this basic gaze following behavior, suggested to rely on a simple reflexive mechanism and believed to be an important prerequisite for complex forms of social cognition. Pet dogs differ from other species in that they follow only communicative human gaze clearly addressed to them. However, in an earlier experiment we showed that wolves follow human gaze into distant space. Here we set out to investigate whether domestication has affected gaze following in dogs by comparing pack-living dogs and wolves raised and kept under the same conditions. In Study 1 we found that in contrast to the wolves, these dogs did not follow minimally communicative human gaze into distant space in the same test paradigm. In the observational Study 2 we found that pack-living dogs and wolves, similarly vigilant to environmental stimuli, follow the spontaneous gaze of their conspecifics similarly often. Our findings suggest that domestication did not affect the gaze following ability of dogs itself. The results raise hypotheses about which other dog skills might have been altered through domestication that may have influenced their performance in Study 1. Because following human gaze in dogs might be influenced by special evolutionary as well as developmental adaptations to interactions with humans, we suggest that comparing dogs to other animal species might be more informative when done in intraspecific social contexts.
\end{abstract}

Keywords: Canis lupus, Canis familiaris, gaze following, distant space, comparative study

Following others' gaze into distant space can help to obtain relevant information about one's social and physical environment, such as the presence and location of food, predators, and conspe- cifics (Tomasello, Hare, \& Fogleman, 2001). Therefore, monitoring others' head/gaze and eye orientation is a central feature of social life in humans and other social animals (Brooks \& Meltzoff,
This article was published Online First May 30, 2016.

Geraldine Werhahn, Wolf Science Center, Ernstbrunn, Austria and Wildlife Conservation Research Unit, The Recanati-Kaplan Centre, Department of Zoology, University of Oxford; Zsófia Virányi, Wolf Science Center and Messerli Research Institute, University of Veterinary Medicine Vienna, Medical University Vienna, University of Vienna; Gabriela Barrera, Wolf Science Center and Research Institute of Veterinary Science (ICiVet - Litoral) - UNL - CONICET; Andrea Sommese, Wolf Science Center; Friederike Range, Wolf Science Center and Messerli Research Institute, University of Veterinary Medicine Vienna, Medical University Vienna, University of Vienna.

The project was financially supported by Austrian Science Fund (FWF) project P21244-B17. Writing was supported by ERC Starting Grant CanCoop (311870) to Friederike Range and by the WWTF project CS11-026 to Zsófia Virányi. We thank Marianne Heberlein for the statistical analysis. We further thank many private sponsors including Royal Canin for financial support and the Game Park Ernstbrunn for hosting the Wolf Science Center. We would like to acknowledge all the dogs and wolves living at the Wolf Science Center for being wonderful study objects, and thank all the many students and volunteers for their devotion and assistance with raising the animals.

This research complies with the current Austrian laws on animal protection.

Correspondence concerning this article should be addressed to Geraldine Werhahn, Wildlife Conservation Research Unit, The Recanati-Kaplan Centre, Department of Zoology, University of Oxford, Tubney House, Abingdon Road, Tubney, Abingdon OX13 5QL, United Kingdom. E-mail: geraldine.werhahn@zoo.ox.ac.uk 
2002). Several species, ranging from nonhuman primates (Amici, Aureli, Visalberghi, \& Call, 2009; Bräuer, Call, \& Tomasello, 2005; Povinelli \& Eddy, 1996; Teufel, Gutmann, Pirow, \& Fischer, 2010; Tomasello, Call, \& Hare, 1997) through goats Capra hircus (Kaminski, Riedel, Call, \& Tomasello, 2005), rooks Corvus frugilegus (Schloegl, Schmidt, Scheid, Kotrschal, \& Bugnyar, 2008), and bald ibises Geronticus eremita (Loretto, Schloegl, \& Bugnyar, 2010) to red-footed tortoises Geochelone carbonaria (Wilkinson, Mandl, Bugnyar, \& Huber, 2010) have been shown to follow others' gaze into distant space (D'Entremont, Hains, \& Muir, 1997; Shepherd, 2010), and in most species this skill emerges relatively early during development. For instance, rhesus macaques Macaca mulatta follow gaze from the age of 5.5 months on (Tomasello, Hare, \& Fogleman, 2001), wolf pups follow gaze at Week 14 (Range \& Virányi, 2011), and common ravens Corvus corax show the skill soon after fledging (Bugnyar, Stöwe, \& Heinrich, 2004; Schloegl, Kotrschal, \& Bugnyar, 2007). Human infants follow gaze within their first year (Brooks \& Meltzoff, 2005; D'Entremont, Hains, \& Muir, 1997), whereas chimpanzees, Pan troglodytes, follow human gaze reliably at the age of 3-4 years (Tomasello, Hare, \& Fogleman, 2001).

Its early development and universality suggest that gaze following into distant space relies, at least partially, on a reflexive mechanism (Shepherd, 2010). Despite of this, gaze following does not occur after every gazing event an individual happens to observe: Greylag geese, Anser anser, followed $37 \%$ of the gaze cues they could observe (Kehmeier, Schloegl, Scheiber, \& Wei $\beta$, 2011), goats 57\% (Kaminski, Riedel, Call, \& Tomasello, 2005), and common ravens 67\% (Schloegl, Kotrschal, \& Bugnyar, 2007). In general, gaze following occurs in a flexible and context-specific way, which indicates that learning mechanisms fine-tune the occurrence of this behavior (Goossens, Dekleva, Reader, Sterck, \& Bolhuis, 2008; Micheletta \& Waller, 2012; Ricciardelli, Carcagno, Vallar, \& Bricolo, 2013; Shepherd, 2010; Shepherd, Deaner, \& Platt, 2006). In accordance, longtailed macaques Macaca fascicularis have been shown to modulate their gaze following response according to a human demonstrator's facial expression, that is, they reacted more frequently if her face was signaling fear/submission compared with a neutral expression (Goossens, Dekleva, Reader, Sterck, \& Bolhuis, 2008). Furthermore, the relationship of the interacting individuals influences gaze following, demonstrated for example by a faster gaze following in dyads of crested macaques Macaca nigra characterized by friendship, in comparison to dyads of not closely bonded individuals (Micheletta \& Waller, 2012). More important, however, animals of various species ranging from common ravens through wolves to primates, at least when socialized with humans, readily follow also human gaze into distant space (Bräuer, Call, \& Tomasello, 2005; Range \& Virányi, 2011; Schloegl, Kotrschal, \& Bugnyar, 2007; Tomasello, Hare, \& Fogleman, 2001).

Therefore, it is rather surprising that pet dogs Canis familiaris, in contrast to these wild species, do not follow human gaze into distant space when tested with methods comparable with the above studies (Agnetta, Hare, \& Tomasello, 2000; Duranton, Range, \& Virányi, in preparation). These results need further explanation from an evolutionary perspective, because of domestication and their extensive experiences with humans, one would expect that pet dogs perform better at using human-given cues than nondomesticated species (Hare, Brown, Williamson, \& Tomasello, 2002;
Gácsi et al., 2009; Miklósi et al., 2003), but also from a mechanistic perspective because dogs do follow human gaze cues in foraging contexts in which the target of the gaze cue is clearly defined (Met, Miklósi, \& Lakatos, 2014; Duranton, Range, \& Virányi, in preparation). Only recently data have emerged that may explain these discrepancies. Paradoxically, one explanation might be that the high exposure of dogs to interactions with humans prevents them from following the kinds of gaze cues, which are typically used in gaze-following studies. Most studies on other species have used noncommunicative or minimally communicative human gaze cues (Bräuer, Call, \& Tomasello, 2005; Tomasello, Hare, \& Fogleman, 2001). Although the experimenters have made sure that the subjects paid attention to them before delivering the gaze cue (e.g., by waiting for the right moment or by feeding the subjects before the gaze cue), they did not specifically address the subject by calling it and giving different ostensive cues such as lifting the eye-brows and/or forming eye-contact with the subject (for an exception on calling the subject's name, see Schloegl, Kotrschal, \& Bugnyar (2007)). Because such ostensive cues are unique to human communication, it is understandable that studies on nondomesticated species did not feel the need to investigate their effects on gaze-following behavior. Pet dogs however have plenty of opportunities to learn that only gaze-cues that are preceded with such cues are relevant for them (Tauzin, Csík, Kis, \& Topál, 2015). Additionally, during their everyday life shared with humans, they may also habituate to noncommunicative gaze cues of humans who are interested in many more things than relevant for dogs (Miklósi A., personal communication)

Supporting this hypothesis, dogs do follow human gaze cues into distant space if the cue has been presented in a repeated and clearly communicative way after addressing the dog (Duranton, Range, \& Virányi, in preparation; Wallis et al., 2015, see also Téglás et al., 2012). This is in line with other findings showing that also in other contexts (e.g., when learning how to solve a problem) dogs use human-given information specifically if it has been addressed to them (Kaminski, Schulz, \& Tomasello, 2012; Pongrácz, Miklósi, Timár-Geng, \& Csányi, 2004; Topál, Gergely, Erdőhegyi, Csibra, \& Miklósi, 2009). It has been suggested that this reflects the evolutionary adaptation of dogs to uniquely human forms of communication and teaching (Topál, Gergely, Erdőhegyi, Csibra, \& Miklósi, 2009; Topál, Kis, \& Oláh, 2014), albeit no research has specifically addressed to what extent individual learning about the role of ostensive-communicative human cues contributes to the above performance of dogs.

Recently it has been shown that individual learning processes do strongly influence to what extent dogs follow human gaze into distant space. Wallis and colleagues (2015) found that dogs that had a higher training score resulting from regular and long-term participation in various dog sports or obedience courses, followed human gaze less than dogs with little or no formal training. Moreover, even short training to initiate eye-contact with the human experimenter disrupted the dogs' gaze following response because after training the dogs spent more time with watching the human instead of following her gaze (Wallis et al., 2015).

More important, the same effects of training and lack of ostensive-communicative cues inhibiting gaze-following in pet dogs were not found in extensively socialized and trained wolves. Wolves, even after having been trained to engage in eye-contact before testing, successfully followed human gaze even though this 
gaze cue was minimally communicative and had no clear target in the environment (Range \& Virányi, 2011). As long as we compare pet dogs and pack-living wolves however, we cannot know whether their differential responsiveness to training and to a lack of ostensive cues reflects different predispositions of dogs that evolved during domestication or is because of their different learning histories. As discussed earlier, because of their more limited exposure to interactions with humans, the pack-living wolves might have learnt less about the relevance of human attention-calling cues, might have habituated less to human-given nonostensive gaze cues or might have responded less or differently to training than pet dogs. Therefore, in the current study we set out to investigate whether domestication has affected gaze following in dogs by comparing pack-living dogs and wolves who had been raised and kept in the same way. In Study 1 we tested dogs on following human gaze into distant space in the same way as the wolves tested by Range and Virányi (2011) after they had received the same training for eye-contact as the wolves. In Study 2 we investigated whether domestication has affected the gazefollowing of dogs using observational methods in an intraspecific context, which is, we compared whether pack-living dogs and wolves spontaneously follow the gaze of their pack-mates to a similar extent. By using experimental and observational methods in inter- and intraspecific contexts, we aimed at gaining a more comprehensive knowledge about gaze following in dogs and wolves to help formulate exact hypotheses regarding the potential effects of domestication.

\section{Study 1: Following Human Gaze Into Distant Space in Dogs}

In this study we investigate whether pack-living dogs, that have been raised and kept under the same conditions as the wolves tested by Range and Virányi (2011) and, therefore, had limited interactions with humans, would follow minimally communicative and no-target human gaze even after training for eye-contact as did the wolves, or if they would perform similarly poorly as the pet dogs in former studies (Agnetta, Hare, \& Tomasello, 2000). For this aim, we repeated the gaze following into distant space experiment that had been previously carried out with the wolves and used exactly the same set-up: all animals had repeated clickertraining sessions to form eye-contact with the experimenter upon hearing the command "look" before the experiment started. Before the gaze cue was given, a few warm-up trials were conducted to establish eye-contact - the subject was called by its name, the look command was given and the subject received a piece of food when it had looked into the eyes of the experimenter. Then once the next eye-contact was established, the experimenter looked either into distant space to one side or the other or gave a control cue looking at the ground in front of the animal. Thus, our experiment had three components that had previously been shown to decrease following human gaze in dogs but not in wolves: (a) it involved training for eye-contact, (b) the gaze cue had no clear target, and (c) was conducted in a minimally communicative context.

\section{Method}

Subjects. All dogs $(n=10)$ that participated in this study were mixed-breed dogs that were born in animal shelters in Hun- gary. Details about the study dogs are given in Table 1. The majority of these study dogs also participated in the observational Study 2 with the exception of the individual that died at the age of 23 weeks. All of the dogs were hand-raised in peer groups in Hungary after being separated from their mothers in the first 10 days after birth. They were bottle-fed and later hand-fed by humans and had continuous access to humans the first 4 months of their life. At the age of 10 weeks the dogs were transferred to the Wolf Science Center, where they are kept in large enclosures. From this age on, there were no humans continuously present in the enclosure, but the dogs participated in training and/or cognitive and behavioral experiments at least once a day and hence had intensive social contact with humans. This raising procedure was used to allow for a comparison of the cognitive abilities between these dogs and the wolves at the Wolf Science Center (for more details on the raising procedure see Range \& Virányi, 2011).

All animals received intensive obedience training like sit, down, roll-over and eye contact on a daily basis using the clicker (operant conditioning with a secondary reinforcer). This training assures that the animals are cooperative and attentive toward humans and also allows veterinary checks without sedating the animals. In the eye contact training, the animals were rewarded for looking into the trainer's eyes. Initially the trainer attracted the animal's attention in various ways, and when eye-contact was formed she marked this behavior with the clicker and gave a piece of food to the subject. Later during the training the look command was introduced to request eye-contact from the animals. Throughout the training, the trainer looked only at the animals, and even if she occasionally got distracted and looked to another direction, the animals were never rewarded for following her gaze. All animals, wolves and dogs, were trained until they were able to establish eye contact on request (look), with the hand of the trainer containing the food reward stretched out to one side, before the study started.

A testing room $(6 \times 10 \times 6 \mathrm{~m})$ next to the enclosures allowed for training and testing the animals in isolation from the pack. All dogs were worked in separation from the other dogs on a daily basis. The hand-raising and training procedures as well as keeping conditions are identical to how we hand-raise, train, and keep our wolves; therefore, if we find differences in the gaze-following skills of these dogs compared with the wolves these cannot be attributed purely to their different experiences, or specifically, to their different amount of lifelong as well as experimental training to focus on humans.

Experimental procedures. Using the procedure as described in Experiment 2 of the wolf study (Range \& Virányi, 2011), each subject was tested a total of four times with intervals of 3 weeks for their abilities to follow human look-asides, starting at the age of 14 weeks. One subject died before the last test at the age of 23 weeks (see Table 1). Tests were conducted individually in the indoor puppy room, in the indoor testing room or close to the puppy enclosure (after the animals had moved to the pack enclosure). We varied the location from test to test to avoid habituation to the task. Studies were conducted by one of three hand-raisers with a second experimenter assisting for videotaping during experiments.

Each of the four sessions consisted of one look-aside trial and one control trial. At the start of each trial (test and control), the human experimenter (E) asked the subject to sit in front of her and to establish eye contact with her by giving the trained command 
Table 1

Name, Species, Pack Name, Pack Size, Sex, Age, and Relatedness of All Study Animals

\begin{tabular}{|c|c|c|c|c|c|c|c|}
\hline Individual & Species & Pack name & Pack size & Sex & Age (years) & Observation time (min) & Relatedness \\
\hline Nanuk & Wolf & Nanuks ${ }^{\mathrm{b}}$ & 3 & M & 4 & 1,001 & \\
\hline Yukon & Wolf & Nanuks ${ }^{b}$ & 3 & $\mathrm{~F}$ & 4 & 1,001 & Sibling of Geronimo \\
\hline Wapi & Wolf & $\begin{array}{l}\text { Nanuks }^{\mathrm{b}} \\
\text { Wapis }^{\mathrm{a}}\end{array}$ & $\begin{array}{l}3 \\
2\end{array}$ & M & 3 & 1,336 & Sibling of Kenai \\
\hline Kaspar & Wolf & Kaspars $^{\mathrm{a}, \mathrm{b}}$ & $5^{\mathrm{a}} ; 4^{\mathrm{d}}, 3^{\mathrm{e}}$ & M & 5 & 1,065 & \\
\hline Aragorn & Wolf & Kaspars, a,b & $5^{\mathrm{a}} ; 4^{\mathrm{d}}, 3^{\mathrm{e}}$ & M & 5 & 1,090 & Sibling of Shima \\
\hline Shima & Wolf & Kaspars $^{\mathrm{a}, \mathrm{b}}$ & $5^{\mathrm{a}} ; 4^{\mathrm{d}} \cdot 3^{\mathrm{e}}$ & $\mathrm{F}$ & 5 & 1,105 & \\
\hline Cherokee & Wolf & Kaspars $^{\mathrm{a}}$ & 5 & M & 4 & 276 & Sibling of Apachee \\
\hline Apachee & Wolf & Kaspars $^{\mathrm{a}, \mathrm{c}}$ & $5^{\mathrm{a}} ; 4^{\mathrm{d}}$ & M & 4 & 259 & Sibling of Cherokee \\
\hline Kenai & Wolf & $\begin{array}{l}\text { Wapis }^{\mathrm{a}} \\
\text { Kenais }^{\mathrm{e}}\end{array}$ & $\begin{array}{l}2 \\
2\end{array}$ & M & 3 & 703 & Sibling of Wapi \\
\hline Tatonga & Wolf & Geronimos $^{\mathrm{d}}$ & 2 & $\mathrm{~F}$ & 4 & 287 & \\
\hline Geronimo & Wolf & $\begin{array}{l}\text { Geronimos } \\
\text { Kenais }^{\mathrm{d}}\end{array}$ & $\begin{array}{l}2 \\
2\end{array}$ & M & 4 & 650 & Sibling of Yukon \\
\hline Rafiki* & Dog & Rafikis $^{\mathrm{a}, \mathrm{b}}$ & $6^{\mathrm{a}} ; 5^{\mathrm{b}}$ & M & 4 & 969 & \\
\hline Binti* & Dog & Rafikis $^{\mathrm{a}, \mathrm{b}}$ & $6^{\mathrm{a}} ; 5^{\mathrm{b}}$ & $\mathrm{F}$ & 3 & 998 & Sibling of Asali \\
\hline Maisha* & Dog & Rafikis $^{a, b}$ & $6^{\mathrm{a}} ; 5^{\mathrm{b}}$ & M & 4 & 977 & Sibling of Kilio \\
\hline Asali* & Dog & Rafikis ${ }^{\mathrm{a}, \mathrm{b}}$ & $6^{\mathrm{a}} ; 5^{\mathrm{b}}$ & M & 3 & 956 & Sibling of Binti \\
\hline Hakima* & Dog & Rafikis $^{\mathrm{a}, \mathrm{b}}$ & $6^{\mathrm{a}} ; 5^{\mathrm{b}}$ & $\mathrm{M}$ & 3 & 945 & Sibling of Bashira \\
\hline Nuru & Dog & Nurus ${ }^{\mathrm{b}}$ & 4 & $\mathrm{M}$ & 2 & 472 & Sibling of Zuri \\
\hline Zuri & Dog & Nurus $^{\mathrm{b}}$ & 4 & $\mathrm{~F}$ & 2 & 472 & Sibling of Nuru \\
\hline Bora & Dog & Nurus $^{b}$ & 4 & $\mathrm{~F}$ & 2 & 472 & Sibling of Bora \\
\hline Layla & Dog & Nurus $^{\mathrm{b}}$ & 4 & $\mathrm{~F}$ & 2 & 472 & Sibling of Layla \\
\hline Meru* & Dog & Merus $^{\mathrm{a}}$ & 2 & M & 3 & & \\
\hline Kilio* & Dog & $\begin{array}{l}\text { Kilios }^{\mathrm{b}} \\
\text { Merus }^{\mathrm{a}} \\
\text { Kilios }^{\mathrm{b}}\end{array}$ & $\begin{array}{l}4 \\
2 \\
4\end{array}$ & M & 4 & $\begin{array}{l}812 \\
791\end{array}$ & Sibling of Maisha \\
\hline Bashira* & Dog & $\begin{array}{l}\text { Kilios }{ }^{\mathrm{b}} \\
\text { Rafikis }^{\mathrm{a}}\end{array}$ & $\begin{array}{l}4 \\
6^{\mathrm{a}}\end{array}$ & F & 3 & 875 & Sibling of Hakima \\
\hline $\mathrm{Nia}^{*}$ & Dog & Kilios $^{\mathrm{b}}$ & 4 & $\mathrm{~F}$ & 2 & 434 & \\
\hline Tana $^{* \mathrm{f}}$ & Dog & Kilio & 4 & M & NA & NA & \\
\hline
\end{tabular}

Note. The dogs that participated in the experimental study and the observational study are marked with an asterisk $\left({ }^{*}\right)$.

${ }^{a}$ August to September 2011. ${ }^{b}$ March to June $2012 .{ }^{\mathrm{c}}$ until 27 of April 2012, then excluded from the study. ${ }^{\mathrm{d}}$ March 2012 until 27 of April

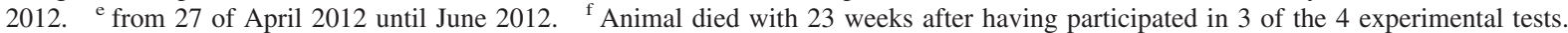

look for which she then rewarded the animal with a click and a piece of food. After 2 to 4 such warm-up trials, depending on whether the animals stayed in front of the experimenter between trials, E asked once again for establishing eye-contact. As soon as the subject looked into her eyes, E gave a gaze cue. All gaze cues involved turning the head and the eyes to the side (test) or to the ground (control) while the body stayed in the same position oriented toward the subject. In test trials, E looked to a point at a 90 degree angle (see Figure 1). In control trials, E looked to a point on the ground just next to the dog instead of looking to the side. We decided not to look directly at the dog in control trials to avoid that the eye-contact encourages the dogs to maintain attention of

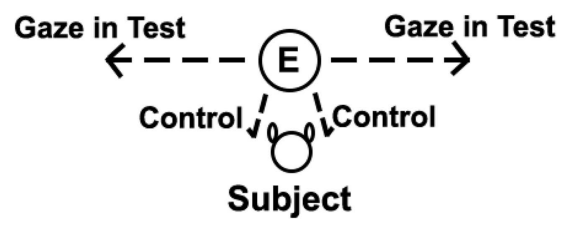

Figure 1. Experimental setup of the gaze following into distant space with human experimenter (E) and test subject facing her. In the test condition, a gaze cue was given to the left or right side, while in the control condition she looked to a point on the ground next to the subject. the human longer in the control than in the test trials. The animals received no reward in either the test or the control trials. The order of control and test trials as well as the direction of the gaze cue (left or right) was randomized within and across subjects. Each gaze cue was given for $10 \mathrm{~s}$ and the subject's response within these 10 s (i.e., whether or not it looked to the same side as E looked in the respective test trial) was noted later from the video records that was taken by a second experimenter standing $3-5 \mathrm{~m}$ behind the dog and holding a hand-held camera. The time interval between trials was at least $10 \mathrm{~s}$; the exact time was dependent on the dog's attention toward $\mathrm{E}$.

Coding and data analysis. All trials were coded from video files using the Solomon coder software (Solomon Coder beta 10.05.06). We used head orientation as criteria for looking to the side as we did in our wolf study (Range \& Virányi, 2011). Accordingly, a head turn was scored if the animal turned its head by at least 45 degrees. Like in the previous study, we first analyzed the latency (max. $10 \mathrm{~s}$ ) of looking into the direction of E's head movement demonstrated in each test trial, and the same variable was measured also in the control trial conducted within the same session. Maximum latency was set at $10 \mathrm{~s}$. Second, as a stricter measurement, we analyzed in each test and control trial the immediate reaction of the dog to the gaze cues by recording whether or not $(1 / 0)$ the first detectable head turn of the subject followed 
the direction of the demonstrated head movement. An immediate response was defined as a response within $2 \mathrm{~s}$ according to previous studies on gaze following (Miklósi et al., 2000; Russell et al., 1997). The time resolution was $0.10 \mathrm{~s}$. Twenty percent of the trials were scored independently by a second observer to assess interobserver reliability (Cohen $\mathrm{ks:}$ look-aside: 0.82 ). To investigate the performance of the dogs, we used McNemar tests to compare single test and control trials. To analyze latencies, we used nonparametric statistics, because the data were not normally distributed based on the Kolmogorov-Smirnov test. Statistical analyses were performed in R 3.2.2 (R Core Development Team, 2009). Results are given for two-tailed tests and $\alpha$ was set at 0.05 .

\section{Results and Discussion}

When analyzing the latencies over the total cue presentation of $10 \mathrm{~s}$, we found that only in the fourth testing session at 23 weeks of age the subjects had a significantly shorter latency to look into the demonstrated direction in the test than in the control trials (Wilcoxon signed-ranks test with continuity correction: 23 weeks: $N=9$ (3 ties), $\mathrm{V}=0, p<.036$ ). When we looked at the immediate response (i.e., the first head turn) of the animals, we found, however, that in fact few animals ever reacted within $2 \mathrm{~s}$ after the gaze cue had started. Specifically at earlier ages (14 and 17 weeks) none of the animals looked to the indicated direction within $2 \mathrm{~s}$ either in the test or control trials (McNemar tests: $p>$ $.05)$. At the age of 20 weeks only 3 of 10 and at the age of 23 weeks only three of nine animals followed the gaze into the indicated direction within $2 \mathrm{~s}$, and interestingly, the three animals reacting were not identical in these two testing sessions (McNemar tests: $p>.05)$.

In summary, despite positive results with wolves using exactly the same methods (Range \& Virányi, 2011), dogs did not follow a human gaze cue into distant space in this study. That is, their performance was more similar to the poor performance of pet dogs when tested with a noncommunicative and no-target gaze cue or after extensive training for eye-contact (Agnetta, Hare, \& Tomasello, 2000; Duranton, Range, \& Virányi, in preparation; Met, Miklósi, \& Lakatos, 2014; Téglás, Gergely, Kupan, Miklósi, \& Topál, 2012; Wallis et al., 2015) than to the wolves, indicating that domestication has likely altered some skills of dogs that influence their performance in this task.

\section{Study 2: Spontaneous Following of Conspecifics Gaze}

To address the question whether domestication has affected gaze following in dogs, we observed the same wolves and dogs raised and kept under identical conditions within their captive packs and investigated whether they follow conspecific gaze during spontaneous naturalistic within-pack interactions. Our aim was to compare intraspecific gaze following in a natural social context that is evolutionarily relevant not only for wolves and dogs but also for other social species.

Observational studies on gaze following in mammals are rare so far. This is probably because of the difficulties one has to face when recording behavior as subtle as slight eye-movements and coordinated head-turns. Nevertheless, Teufel, Gutmann, Pirow, and Fischer (2010) successfully used observation in their natural environment to document the ontogeny of gaze following in Bar- bary macaques Macaca sylvanus. Similarly, we applied an observational approach to study intraspecific gaze following into distant space, for the first time, in wolves and dogs kept in packs.

\section{Method}

Subjects. Studied animals were 11 adult wolves Canis lupus ( 8 males and 3 females, mean age: 4 years \pm 1 year) originating from North America and 13 dogs Canis familiaris ( 7 males and 6 females, mean age: $3 \pm 1$ year, Table 1). The study dogs were principally the same animals as in the experimental study, with differences being the four additional animals of Nurus pack that have been born after the experimental study was conducted and the absence of the dog that had died previously. The observed wolves were mostly the same wolves as included in the analogue experimental study with wolves described by Range and Virányi (2011).

Procedure. Data collection was conducted from August to September 2011 by G. Barrera and March to June 2012 by G. Werhahn, and distributed randomly over light hours of the days while moving from one pack to the next in a randomized order. Both observers did not participate in handling, care taking or training of the study animals to minimize their interest in these persons, and also during the observations they moved quietly on the outside of the enclosures and did not interact with the study animals. Gaze events induced by the observers were not included in the analyses. All observations were conducted in the living enclosures of the wolf and dog packs. We observed the different packs for a total time of $88 \mathrm{hr} 30 \mathrm{~min}$; wolf packs were observed for $51 \mathrm{hr} 21 \mathrm{~min}(57.65 \%)$ of this time, dog packs for $37 \mathrm{hr} 29 \mathrm{~min}$ $(42.35 \%)$ of the time. During the observations, we started video recording whenever at least two animals were within $10 \mathrm{~m}$ of each other, and thus the opportunity was given that the animals could see each other. Using a hand-held camera, we went on video recording the animals continuously until a head-turn of one of them provided a gaze following possibility to the other animals or until all animals moved out of the camera range. This resulted in $29 \mathrm{hr} 8 \mathrm{~min}$ of video material of situations where gaze following could potentially have occurred; $43 \%$ documenting wolves and $57 \%$ documenting dogs.

Behavioral analyses. Later on, from the video recordings we coded different gazing events, defined as an abrupt head turn to the left or right side of one or more animals triggered either by some random natural or human-related stimuli (e.g., sound, visual movement) in the environment or by the gaze cue of another animal. All gazing events we categorized into four different types: gaze cue, gaze following, independent look, and simultaneous gazing (see also Table 2). A gaze cue was recorded when one single animal (the model) turned its head with a continuous movement and looked for at least $2 \mathrm{~s}$ into a new direction that neither the model nor another individual had looked into within the preceding $10 \mathrm{~s}$ (presumably reacting to an external stimulus that had just occurred). Besides gaze cues, we coded simultaneous gazing when multiple animals (presumably all reacting to the same stimulus) turned their heads simultaneously with a continuous movement into a new direction that neither animal had looked into during the previous $10 \mathrm{~s}$. Again, gazing into the new direction had to last a minimum of $2 \mathrm{~s}$. Gaze cues and simultaneous looking were used to compare the vigilance (responsiveness to external stimuli) of dogs and wolves. Because the enclosures of the wolves and dogs where 
Table 2

Overview of the Behaviors Recorded From the Videos, and the Behavioral Variables Calculated Based on Them and Used in the Statistical Analyses

\begin{tabular}{|c|c|c|}
\hline Behavior & Behavioral variable & Definition \\
\hline \multicolumn{3}{|c|}{$\begin{array}{l}\text { Gaze cue: One single animal (the model) turns its head and looks for at least } 2 \mathrm{~s} \text { into a new direction that } \\
\text { neither the model nor another individual had looked into within the preceding } 10 \mathrm{~s} \text { (presumably reacting } \\
\text { to an external stimulus that had just occurred). }\end{array}$} \\
\hline & Gaze cue frequency & $\begin{array}{l}\text { Number of gaze cues of an individual/ } \\
\text { total duration of video recording its } \\
\text { pack }\end{array}$ \\
\hline \multicolumn{3}{|c|}{$\begin{array}{l}\text { Simultaneous gazing: Multiple animals (presumably all reacting to the same stimulus) turn their heads } \\
\text { simultaneously and look for at least } 2 \mathrm{~s} \text { into a new direction that neither animal had looked into during the } \\
\text { previous } 10 \mathrm{~s} \text {. }\end{array}$} \\
\hline & Simultaneous gazing frequency & $\begin{array}{l}\text { Number of simultaneous gazing events of } \\
\text { an individual/total duration of video } \\
\text { recording its pack }\end{array}$ \\
\hline & Vigilance & $\begin{array}{l}\text { Gaze cue frequency }+ \text { simultaneous } \\
\text { gazing frequency }\end{array}$ \\
\hline \multicolumn{3}{|c|}{$\begin{array}{l}\text { Gaze following: After a gaze cue, within } 2 \mathrm{~s} \text {, another animal (the observer) looks in the same direction as } \\
\text { the model for at least } 2 \mathrm{~s} \text {, given that the model was within the } 90 \text { degree visual field of the observer and } \\
\text { the observer had its head up and its eyes open during the gaze cue. }\end{array}$} \\
\hline & Gaze following frequency & $\begin{array}{l}\text { Number of gaze following events of an } \\
\text { individual/total duration of video } \\
\text { recordings its pack }\end{array}$ \\
\hline & Gaze following rate & $\begin{array}{l}\text { Number of gaze following events of an } \\
\text { individual/number of gaze cues this } \\
\text { individual could see }\end{array}$ \\
\hline \multicolumn{3}{|c|}{$\begin{array}{l}\text { Independent look: After a gaze cue, within } 2 \mathrm{~s} \text {, another animal looks in the same direction as the "model" } \\
\text { for at least } 2 \mathrm{~s} \text {, given that the model was NOT within the } 90 \text { degree visual field of the observer. }\end{array}$} \\
\hline
\end{tabular}

within the same general area, we assumed that the frequency and intensity of random stimuli in the environment were the same for wolves and dogs and stayed constant over the study periods. The independence of these data points has been assured by including only gaze cues and simultaneous gazing in the analyses that were a minimum of 2 min apart in time and between which the relative spatial position of animals had changed.

Beyond describing vigilance, gaze cues as well as simultaneous looks could potentially allow for gaze following in one or more other observing individual(s). We recorded gaze following when such a gaze cue by the model(s), with a short delay but within $2 \mathrm{~s}$, was followed by another animal (the observer) turning its head continuously to look in the same direction for at least $2 \mathrm{~s}$. We recorded gaze following only if the model was within the 90 degree visual field of the observer and the observer had its head up and its eyes open, to make sure that the observer could see the model's gaze cue. If this was not the case (i.e., the relative positioning of the model and observer prevented the observer from seeing the model's gaze cue), the observer's look to the same direction as the model's gaze cue was to be coded as an independent look. We coded independent looks when the model was clearly outside of the 90 degree visual field of the observer, and therefore, could not have reacted to the model's gaze cue. With coding this behavior we wanted to investigate how often the animals reacted to the same external stimulus with a short delay, which is in a manner that could be confused with gaze following. We hypothesized that the more independent looks we see the more likely it is that some of the gazing events that we coded as gaze following represent false positive data because the observers in reality reacted directly to the same external stimulus as the model rather than to the model's head turn. However, we detected not a single independent look. During data collection, notes on the possible environmental triggers of gazing events were made. However, because possibly many different triggers might have played a role and the human observers were not in the position to judge what exactly the canine subjects heard, saw, and responded to, the triggers could not be determined reliably enough to include them in the analysis as a random effect.

All videos were coded by G. Werhahn and A. Sommese with the Solomon Coder beta 12.09.04 (copyright by András Péter, http://solomoncoder.com/). Gaze cues, simultaneous gazing events, gaze following, and independent looks were coded strictly applying the definitions given above. Based on the number of different gazing events detected in each individual and by using the total duration of all video recordings for its pack, we calculated the frequencies of the gaze cues, simultaneous gazing events, and gaze followings of each individual. Further on, we calculated the gaze following rate of each individual by dividing its number of gaze following events with the number of gaze cues of its pack mates the subject had the chance to see. For an overview of the behavioral variables used in the analysis, which are indicated by italics in the methods and results, see Table 2.

The interobserver reliability was calculated after G. Werhahn and A. Sommese independently coded $20 \%$ of the analyzed video material: Spearman rank correlations: gaze cue frequency: $\mathrm{r}_{\mathrm{s}}=$ 0.84; simultaneous gazing frequency: $\mathrm{r}_{\mathrm{s}}=0.84$, gaze following frequency: $\mathrm{r}_{\mathrm{s}}=0.93$ ).

Statistical analysis. To compare dogs and wolves on their general vigilance, gaze cue and simultaneous gazing frequencies as 
well as the sum of these two, that is, vigilance, were analyzed with generalized linear mixed effect models (GLMM) using Poisson distribution. Models were based on a Bayesian approach and the data of each individual was treated as a separate data point. We tested for species as main effect in the models and controlled for pack size. Further on, individual nested within pack was included as a random factor. To compare dogs and wolves in their simultaneous gazing frequency, we calculated a GLMM using a binomial distribution with pack size as a random factor using a model based on a Bayesian approach. For analyzing the above mentioned models we used the MCMCglmm library from R 3.2.2 (R Core Development Team, 2009). To compare whether a different proportion of dogs and wolves reacted with a head turn, that is, gaze following, in the recorded events we calculated a GLMM based on a binomial error distribution that included individuals nested within pack as random factor and were controlled for pack size. The analysis has been conducted with lme4 library from R 3.2.2 (R Core Development Team, 2009).

\section{Results and Discussion}

In the dogs, we documented a total of 25 simultaneous gazing events and 35 gaze cues, resulting in 11 gaze followings. In the wolves, we recorded 19 simultaneous gazing events and 18 gaze cues, resulting in 10 gaze followings. We did not find any independent look in either species.

Vigilance toward external stimuli. To test whether dogs and wolves differ in their general responsiveness toward external stimuli in form of a head turn reaction, we compared the frequencies of their gaze cues and simultaneous gazing, and we calculated the sum of these two variables to describe the vigilance of dogs and wolves. Vigilance did not differ between wolves and dogs (GLMM: pMCMC $=0.93$; Figure 2), and this was the same for the simultaneous gazing frequency (GLMM: pMCMC $=0.96$, Figure 2 ) and the gaze cue frequency (GLMM: pMCMC $=0.82$, Figure 2). Moreover, also the mean percentage of animals reacting to each external stimulus with a gaze reaction (out of all animals being within $10 \mathrm{~m}$ distance to each other and, therefore, in the position to react to this stimulus) was similar between dogs and wolves, with means and $95 \%$ confidence intervals (CIs) of $72 \% \pm 13$ for wolves and $49 \% \pm 11$ for $\operatorname{dogs}\left(\mathrm{GLMM}: \mathrm{t}_{20}=2.03, p=.06\right)$.

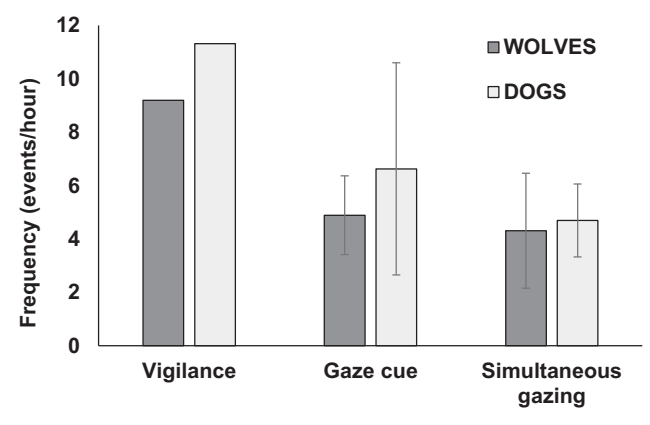

Figure 2. Comparison of the mean vigilance of dogs and wolves which describes the sum of gaze cues and simultaneous gazings between dogs and wolves. The $95 \%$ confidence intervals are given for the gaze cue and simultaneous gazing frequencies. All frequencies were calculated relative to the total duration of video recordings on each pack. No significant differences have been found in these frequencies between the two species.
Gaze following. Both dogs and wolves followed their conspecifics' gaze into distant space with comparable gaze following rates (GLMM: $\chi_{1}^{2}=2.71, p=.10$; Figure 3 ). As reported above, no significant difference was found in the gaze cue frequencies, describing the opportunities for gaze followings per time, between the two species.

In our observational study, we observed that both wolves and dogs spontaneously followed their conspecifics gaze into distant space in a naturalistic social setting. We found no influence of pack size on the gaze following rate. Dogs and wolves appeared similar in their vigilance toward random triggers in their game park environment, providing a similar amount of opportunities for gaze following to occur, and they proved to be similar also in their gaze following rates. More important, we coded gaze following in a conservative way. First, we only coded gaze following if the observer was visibly attentive and the model was within the 90 degree visual field of the observer, which is a rather conservative approach, given that most dogs have a larger visual field (Miller \& Murphy, 1995). Second, we were strict in selecting our video material used for coding, including only events with situations clearly fulfilling our definitions. Further on, we introduced a separate behavioral variable (independent looks) to investigate the likelihood of coding false positive gaze following events. Because we may wrongly record gaze following if two animals react independently to the same external stimulus with a short delay between their reactions, we investigated how often this happened in situations when gaze following was not possible because the second looker could not see the first looker. We could not record a single case when there was a delay between the independent looks of two animals reacting to the same trigger. This makes it unlikely that our gaze following events reflect independent and delayed reactions of two animals to the same external stimulus.

In this study the wolves followed $56 \%$ and the dogs $42 \%$ of their packmates' gaze cues. Albeit this is not directly comparable to studies with other species because of methodological differences, the numbers are relatively similar to the rate of gaze following found in other species (Kehmeier, Schloegl, Scheiber, \& Weiß, 2011: $37 \%$ in greylag geese; Kaminski, Riedel, Call, \& Tomasello, 2005: 57\% in goats; Schloegl, Kotrschal, \& Bugnyar, 2007: 67\% in common ravens). The only study (Teufel, Gutmann, Pirow, \& Fischer, 2010) comparable with ours in terms of methods, however, reported a higher gaze following rate of $70 \%$ in Barbary macaques. Beyond possible species differences, various explanations may contribute to this difference. First of all, we applied a very conservative coding scheme that might have excluded situations where gaze following occurs with a higher rate. We standardized our data collection by recording only those pack situations where a minimum of two animals were less than $10 \mathrm{~m}$ apart. Therefore, all interactions over larger distances or active interactions like playing were excluded from the analyses. Second, the captive living conditions of our study animals may not be ideal for investigating spontaneous gaze following in social groups. Living in enclosures can limit interactions that may elicit gaze following in wild animals, such as engaging in hunting of large animals, where communication via gaze may play an important role (Range \& Virányi, 2011). Habituation to external stimuli typical to game parks may further increase the effect of life in enclosures. Finally, recording gaze following in a limited set of contexts may be linked also to the question how other behaviors of the model accompa- 


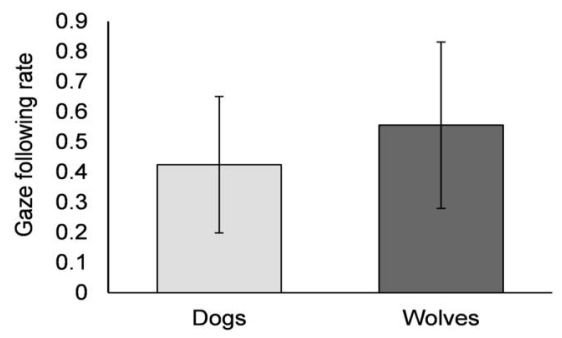

Figure 3. Gaze following rate with $95 \%$ confidence intervals. It describes the amount of gaze followings relative to gaze cues received per individual. The gaze following rates of $0.42 \pm 0.23$ in dogs and $0.56 \pm 0.28$ in wolves did not differ.

nying its gaze cue may influence following its gaze by others. In Barbary macaques gaze following in all age classes was enhanced if a gaze cue was accompanied by a facial expression (Teufel, Gutmann, Pirow, \& Fischer, 2010). Because also wolves and dogs, adapted to live in complex social groups, show highly variable communicative behaviors (Mech, 1970), one can expect that their vocalizations, body, and facial expressions play an important role in eliciting gaze following. Hence, the relatively low gaze following rate we observed may be partly explained by not considering accompanying behaviors and thereby including gaze cues irrelevant for the observer based on the model's behavior.

\section{General Discussion}

We report two comparisons of gaze following into distant space in dogs and wolves raised and kept in the same way based on an experimental and observational study. In our experimental study we found that, in contrast to the wolves but similarly to pet dogs, pack-living dogs did not follow a minimally communicative and no-target human gaze after training for eye-contact. The same dogs and wolves, however, followed the gaze of their conspecific packmates to a similar extent during spontaneous interactions in our second observational study. Before proposing a potential effect of domestication, it is important to consider whether there are alternative explanations for the apparently contradictory findings of the two studies.

As the dogs were 14 to 23 weeks old in Study 1 and 2 to 4 years old in Study 2, one may argue that in Study 1, the different behavior of dogs compared with the wolves can be explained by the later development of gaze-following in dogs than in wolves. For the following reasons, however, we do not think that the younger age of the dogs explains why they did not follow gaze in Study 1 but followed gaze in Study 2. Because wolves and dogs are genetically so close that they are capable of producing fertile offspring (Vilà et al., 2003; Vilà \& Wayne, 1999), it seems reasonable to assume that they develop with the same speed. Indeed their sensory development is comparable (Lord, Feinstein, Smith, \& Coppinger, 2013) and only minimal differences (ca. 2 weeks) have been observed in their locomotory development (Frank \& Frank, 1982; Packard, 2003). Of course, this does not necessarily exclude bigger differences in their cognitive development. Such differences have so far been reported only in respect to human-directed social behavior of dogs and wolves and their use of human-given cues, and all results indicate a faster development in dogs than in wolves (Gácsi et al., 2009; Zimen, 1987). This is in contrast with our findings that at the age of 14 weeks (when tested for the first time) the proportion of wolves following human gaze was higher than the percentage of dogs doing so at the age of 23 weeks. Moreover, as discussed in the introduction, gazefollowing into distant space is thought to rely on a simple, reflexive mechanism, and accordingly develops very early in most species (Shepherd, 2010). Finally, testing pet dogs from 6 months on when we stopped testing our dogs, Wallis and colleagues (2015) found no developmental improvement in the gaze following skills of pet dogs: half to 1 year old dogs followed human gaze into distant space as successfully as any other age groups up to 10 years and more.

Second, because our dogs were raised and kept under the same conditions as the wolves tested by Range and Virányi (2011), we can also exclude that their different lifelong experiences explain either their responsiveness to the human-given gaze cue or to the eye-contact training both dogs and wolves received before being tested. For these reasons, we suggest that the poor performance of the dogs in following human gaze into distant space reflects a difference in the genetic predisposition of dogs and wolves that evolved during the course of domestication. The question, however, is what exactly might have changed.

Considering the universality of gaze following into distance space across species, the low level underlying mechanisms, and the findings of our observational study demonstrating that dogs and wolves followed their pack mates' gaze similarly often, it seems unlikely that domestication has affected the gaze-following ability of dogs in itself. Taken into account that $76-83 \%$ of the world's dog population represents free ranging dogs (Hughes \& Macdonald, 2013; Lord, Feinstein, Smith, \& Coppinger, 2013), we suggest that from an evolutionary perspective the similar performance of dogs and wolves in Study 2 is not surprising because relevant components of the social ecology of free-living dogs and wolves are rather comparable. Free-ranging dogs retained important aspects of the social organization of wolves in regard to dominance relationships, affiliative social interactions, leadership and coalition formation (Bonanni, Cafazzo, Valsecchi, \& Natoli, 2010b; Bonanni, Valsecchi, \& Natoli, 2010a; Cafazzo, Valsecchi, Bonanni, \& Natoli, 2010; Mech, 1970). Because most of these social interactions shared by dogs and wolves likely require some form of visual coordination between pack-members (Range \& Virányi, 2011), gaze following should be as important for dogs as it is for wolves when interacting with conspecifics.

Therefore, it is more likely that domestication has affected some skills of dogs that influenced their performance only in Study 1. As methodologies of the two studies strongly differed and Study 2 was not an experimental study controlled for various factors, we can only hypothesize why the results of the two studies differed. First, the lack of a clear target to the demonstrator's gaze does not seem to explain the poor performance of dogs because both studies used a distant space paradigm without a clear target being present. However, Study 1 differed from Study 2 in respect to (a) using a human as a demonstrator who gave a minimally communicative gaze cue and (b) prior training for eye-contact specifically to the demonstrator.

Second, because we did not code the conspecific models' behavior accompanying their gaze cue in Study 2, we cannot exclude that these gaze cues were better embedded in an emotional/com- 
municative context, and thus, were more relevant to the subjects than the noncommunicative gaze cue used in Study 1. An interesting find was that even if that was the case only dogs responded to this possible difference by following noncommunicative human gaze less than gaze cues in Study 2, in contrast to the wolves that readily followed gaze in both situations. Therefore, one hypothesis regarding the effects of domestication that might explain our results is a difference in the genetic predispositions of dogs and wolves in regard to their sensitivity to their human partners' behavior accompanying gaze cues. This sensitivity could reflect an adaptation of dogs specifically to human-given ostensivecommunicative cues as suggested by Kaminski, Schulz, and Tomasello (2012); Topál, Gergely, Erdőhegyi, Csibra, and Miklósi (2009); and Topál, Kis, and Oláh (2014). Alternatively, however, this sensitivity of dogs may rely on a broader range of behavioral reading skills possibly characterizing both dogs and wolves as well as other social species that enable animals to learn which emotional expressions, attentional cues, and other behavioral details of their group mates indicate that their behavior (including their gazing direction) is worthwhile to pay attention to (Goossens, Dekleva, Reader, Sterck, \& Bolhuis, 2008; Teufel, Gutmann, Pirow, \& Fischer, 2010). In this case, the higher sensitivity of dogs than wolves to the absence of human-given attention-calling cues would indicate that because of domestication dogs can easier extend these skills to human behavior than wolves. Before such a conclusion can be reached, further research needs to examine whether wolves have a similar sensitivity to their pack mates' emotional/attentional expressions as dogs have toward humans (Téglás, Gergely, Kupan, Miklósi, \& Topál, 2012; Topál, Gergely, Erdőhegyi, Csibra, \& Miklósi, 2009; Turcsán, Szánthó, Miklósi, \& Kubinyi, 2015;).

Third, Study 1 differed from Study 2 in having applied a training context in which the subjects were asked to establish eye-contact with the demonstrator before the gaze cue. Because lifelong training as well as short, experimental training for eye-contact reduces gaze following in pet dogs (Wallis et al., 2015), it may be that this training context in itself led to poorer performance in Study 1 than in Study 2. However, again, only the dogs responded to this procedural difference whereas the wolves performed well in both studies. Consequently, the poorer performance of dogs in Study 1 compared to wolves may reflect a difference in their genetic predispositions that affect their responsiveness to such training. Preliminary results of another study show that dogs respond better than wolves to training to establish eye-contact with humans (Gácsi et al., 2009), but further research needs to address whether this different responsiveness is specific to this task or it reflects a difference between dogs and wolves in their trainability in general (Frank, 1980; Frank, 2011) or in their distractibility (wolves having a lower threshold of responding to changes in their environment in contrast to dogs who can better focus on anything that is in their interest at that moment).

Alternatively, dogs and wolves might have responded similarly to the training (i.e., their focusing on the experimenter's face increased to a similar extent) but they may have started and thus also ended at a different level of attentiveness. This hypothesis suggests that because of domestication dogs and wolves have differential tendencies to attend to human faces (Gácsi et al., 2009; Miklósi et al., 2003; Virányi et al., 2008). If so, in the wolves training for eye-contact may have resulted in looking at human faces enough to notice and respond to gaze cues. In dogs, in contrast, assuming that they were more attentive to the human face already before training, training might have caused a fixation on the human face, thereby impeding gaze following, as suggested by results on pet dogs (Wallis et al., 2015). Although we did not test our dogs and wolves before training in this study, results from other experiments show that indeed also in these pack-living populations kept at the Wild Science Center dogs look at humans earlier and longer in problem-solving situations than wolves (da Silva Vasconellos et al., under review; Heberlein, Turner, Range \& Virányi, submitted).

While further research needs to test the above hypotheses, we conclude that our results confirm that domestication did affect the behavior of dogs in a way that influences their following human gaze into distant space at least after training for eye-contact. Future research needs to clarify whether and how domestication impacted on following conspecific and human gaze. Are dogs more sensitive than wolves to behavioral cues that accompany such directional gaze cues in humans? Do dogs and wolves respond differently to training to establish eye-contact or do they rather have a differential tendency to look into human faces? The study of gaze following in canines should systematically manipulate the general social contexts, the model's behavior accompanying the gaze cues and the social relationship between the involved parties. Including these variables will increase our understanding on how flexible canines use gaze following and may help to identify the role of this behavior in the social cognition of wolves and dogs when interacting either with humans or with conspecifics.

\section{References}

Agnetta, B., Hare, B., \& Tomasello, M. (2000). Cues to food location that domestic dogs (Canis familiaris) of different ages do and do not use. Animal Cognition, 3, 107-112. http://dx.doi.org/10.1007/s 100 710000070

Amici, F., Aureli, F., Visalberghi, E., \& Call, J. (2009). Spider monkeys (Ateles geoffroyi) and capuchin monkeys (Cebus apella) follow gaze around barriers: Evidence for perspective taking? Journal of Comparative Psychology, 123, 368-374. http://dx.doi.org/10.1037/a0017079

Bonanni, R., Cafazzo, S., Valsecchi, P., \& Natoli, E. (2010b). Effect of affiliative and agonistic relationships on leadership behaviour in freeranging dogs. Animal Behaviour, 79, 981-991. http://dx.doi.org/10 .1016/j.anbehav.2010.02.021

Bonanni, R., Valsecchi, P., \& Natoli, E. (2010a). Pattern of individual participation and cheating in conflicts between groups of free-ranging dogs. Animal Behaviour, 79, 957-968. http://dx.doi.org/10.1016/j .anbehav.2010.01.016

Bräuer, J., Call, J., \& Tomasello, M. (2005). All great ape species follow gaze to distant locations and around barriers. Journal of Comparative Psychology, 119, 145-154. http://dx.doi.org/10.1037/0735-7036.119.2 .145

Brooks, R., \& Meltzoff, A. N. (2002). The importance of eyes: How infants interpret adult looking behavior. Developmental Psychology, 38, $958-$ 966. http://dx.doi.org/10.1037/0012-1649.38.6.958

Brooks, R., \& Meltzoff, A. N. (2005). The development of gaze following and its relation to language. Developmental Science, 8, 535-543. http:// dx.doi.org/10.1111/j.1467-7687.2005.00445.x

Bugnyar, T., Stöwe, M., \& Heinrich, B. (2004). Ravens, Corvus corax, follow gaze direction of humans around obstacles. Proceedings of the Royal Society B: Biologcial Sciences, 271, 1331-1336.

Cafazzo, S., Valsecchi, P., Bonanni, R., \& Natoli, E. (2010). Dominance in relation to age, sex, and competitive contexts in a group of free-ranging 
domestic dogs. Behavioral Ecology, 21, 443-455. http://dx.doi.org/10 $.1093 / \mathrm{beheco} / \mathrm{arq} 001$

da Silva Vasconcellos, A., Virányi, Z., Range, F., Ades, C., Scheidegger, J. K., Möstl, E., \& Kurt Kotrschal, K. (2016). Training reduces stress in human-socialised wolves to the same degree as in dogs. Manuscript in review. PLOS ONE.

D’Entremont, B., Hains, S. M. J., \& Muir, D. W. (1997). A demonstration of gaze following in 3- to 6-month-olds. Infant Behavior and Development, 20, 560-572.

Duranton, C., Range, F., \& Virányi, Z. (2016). Dogs (Canis familiaris) do follow human gaze into distant space and in an object-choice task, and do so more in communicative contexts. Manuscript in preparation.

Frank, H. (1980). Evolution of canine information processing under conditions of natural and artificial selection. Zeitschrift für Tierpsychologie, 53, 389-399. http://dx.doi.org/10.1111/j.1439-0310.1980.tb01059.x

Frank, H. (2011). Wolves, dogs, rearing and reinforcement: Complex interactions underlying species differences in training and problemsolving performance. Behavior Genetics, 41, 830-839. http://dx.doi.org/ 10.1007/s10519-011-9454-5

Frank, H., \& Frank, M. G. (1982). Comparison of problem-solving performance in six-week-old wolves and dogs. Animal Behaviour, 30, 95-98. http://dx.doi.org/10.1016/S0003-3472(82)80241-8

Gácsi, M., Gyoöri, B., Virányi, Z., Kubinyi, E., Range, F., Belényi, B., \& Miklósi, A. (2009). Explaining dog wolf differences in utilizing human pointing gestures: Selection for synergistic shifts in the development of some social skills. PLoS ONE, 4, e6584. http://dx.doi.org/10.1371/ journal.pone.0006584

Goossens, B. M. A., Dekleva, M., Reader, S. M., Sterck, E. H. M., \& Bolhuis, J. J. (2008). Gaze following in monkeys is modulated by observed facial expressions. Animal Behaviour, 75, 1673-1681. http:// dx.doi.org/10.1016/j.anbehav.2007.10.020

Hare, B., Brown, M., Williamson, C., \& Tomasello, M. (2002). The domestication of social cognition in dogs. Science, 298, 1634-1636. http://dx.doi.org/10.1126/science.1072702

Heberlein, M. T. E., Turner, C. D., Range, F., \& Virányi, Z. (2016). A comparison between wolves (Canis Lupus) and dogs (Canis familiaris) in showing behaviour towards humans. Manuscript submitted for publication.

Hughes, J., \& Macdonald, D. W. (2013). A review of the interactions between free-roaming domestic dogs and wildlife. Biological Conservation, 157, 341-351. http://dx.doi.org/10.1016/j.biocon.2012.07.005

Kaminski, J., Riedel, J., Call, J., \& Tomasello, M. (2005). Domestic goats, Capra hircus, follow gaze direction and use social cues in an object choice task. Animal Behaviour, 69, 11-18. http://dx.doi.org/10.1016/j .anbehav.2004.05.008

Kaminski, J., Schulz, L., \& Tomasello, M. (2012). How dogs know when communication is intended for them. Developmental Science, 15, 222232. http://dx.doi.org/10.1111/j.1467-7687.2011.01120.x

Kehmeier, S., Schloegl, C., Scheiber, I. B., \& Weiß, B. M. (2011). Early development of gaze following into distant space in juvenile Greylag geese (Anser anser). Animal Cognition, 14, 477-485. http://dx.doi.org/ 10.1007/s10071-011-0381-x

Lord, K., Feinstein, M., Smith, B., \& Coppinger, R. (2013). Variation in reproductive traits of members of the genus Canis with special attention to the domestic dog (Canis familiaris). Behavioural Processes, 92, 131-142. http://dx.doi.org/10.1016/j.beproc.2012.10.009

Loretto, M. C., Schloegl, C., \& Bugnyar, T. (2010). Northern bald ibises follow others' gaze into distant space but not behind barriers. Biology Letters, 6, 14-17. http://dx.doi.org/10.1098/rsbl.2009.0510

Mech, D. (1970). The wolf: The ecology and behaviour of an endangered species. Garden City, NY: Natural History Press.

Met, A., Miklósi, Á., \& Lakatos, G. (2014). Gaze-following behind barriers in domestic dogs. Animal Cognition, 17, 1401-1405. http://dx.doi.org/ 10.1007/s10071-014-0754-Z
Micheletta, J., \& Waller, B. M. (2012). Friendship affects gaze following in a tolerant species of macaque, Macaca nigra. Animal Behaviour, 83, 459-467. http://dx.doi.org/10.1016/j.anbehav.2011.11.018

Miklósi, A., Kubinyi, E., Topál, J., Gácsi, M., Virányi, Z., \& Csányi, V. (2003). A simple reason for a big difference: Wolves do not look back at humans, but dogs do. Current Biology, 13, 763-766. http://dx.doi.org/ 10.1016/S0960-9822(03)00263-X

Miklósi, A., Polgardi, R., Topál, J., \& Csányi, V. (2000). Intentional behaviour in dog-human communication: An experimental analysis of "showing" behaviour in the dog. Animal Cognition, 3, 159-166. http:// dx.doi.org/10.1007/s100710000072

Miller, P. E., \& Murphy, C. J. (1995). Vision in dogs. Journal of the American Veterinary Medical Association, 207, 1623-1634.

Packard, J. M. (2003). Wolf behavior: Reproductive, social, and intelligent. In L. D. Mech \& L. Boitani (Eds.), Wolves: Behavior, ecology, and conservation (pp. 35-65). Chicago, IL: University of Chicago Press.

Pongrácz, P., Miklósi, A., Timár-Geng, K., \& Csányi, V. (2004). Verbal attention getting as a key factor in social learning between dog (Canis familiaris) and human. Journal of Comparative Psychology, 118, 375383. http://dx.doi.org/10.1037/0735-7036.118.4.375

Povinelli, D. J., \& Eddy, T. J. (1996). Chimpanzees: Joint visual attention. Psychological Science, 7, 129-135. http://dx.doi.org/10.1111/j.14679280.1996.tb00345.x

Range, F., \& Virányi, Z. (2011). Development of gaze following abilities in wolves (Canis lupus). PLoS ONE, 6, e16888. http://dx.doi.org/10 .1371/journal.pone.0016888

R Core Development Team. (2009). R: A language and environment for statistical computing. Vienna, Austria: R Foundation for Statistical Computing.

Ricciardelli, P., Carcagno, S., Vallar, G., \& Bricolo, E. (2013). Is gaze following purely reflexive or goal-directed instead? Revisiting the automaticity of orienting attention by gaze cues. Experimental Brain Research, 224, 93-106. http://dx.doi.org/10.1007/s00221-012-3291-5

Russell, C. L., Bard, K. A., \& Adamson, L. B. (1997). Social referencing by young chimpanzees (Pan troglodytes). Journal of Comparative Psychology, 111, 185-193. http://dx.doi.org/10.1037/0735-7036.111.2.185

Schloegl, C., Kotrschal, K., \& Bugnyar, T. (2007). Gaze following in common ravens, Corvus corax: Ontogeny and habituation. Animal Behaviour, 74, 769-778. http://dx.doi.org/10.1016/j.anbehav.2006.08.017

Schloegl, C., Schmidt, J., Scheid, C., Kotrschal, K., \& Bugnyar, T. (2008). Gaze following in non-human animals: The corvid example. In $\mathrm{F}$. Columbus (Ed.), Animal behaviour: New research (pp. 73-92). New York, NY: Nova Science Publishers.

Shepherd, S. V. (2010). Following gaze: Gaze-following behaviour as a window into social cognition. Frontiers in Integrative Neuroscience, 4 $1-13$.

Shepherd, S. V., Deaner, R. O., \& Platt, M. L. (2006). Social status gates social attention in monkeys. Current Biology, 16, R119-R120. http:// dx.doi.org/10.1016/j.cub.2006.02.013

Tauzin, T., Csík, A., Kis, A., \& Topál, J. (2015). What or where? The meaning of referential human pointing for dogs (Canis familiaris). Journal of Comparative Psychology, 129, 334-338. http://dx.doi.org/10 .1037/a0039462

Téglás, E., Gergely, A., Kupán, K., Miklósi, Á., \& Topál, J. (2012). Dogs' gaze following is tuned to human communicative signals. Current Biology, 22, 209-212. http://dx.doi.org/10.1016/j.cub.2011.12.018

Teufel, C., Gutmann, A., Pirow, R., \& Fischer, J. (2010). Facial expressions modulate the ontogenetic trajectory of gaze-following among monkeys. Developmental Science, 13, 913-922. http://dx.doi.org/10 .1111/j.1467-7687.2010.00956.x

Tomasello, M., Call, J., \& Hare, B. (1998). Five primate species follow the visual gaze of conspecifics. Animal Behaviour, 55, 1063-1069. http:// dx.doi.org/10.1006/anbe.1997.0636 
Tomasello, M., Hare, B., \& Fogleman, T. (2001). The ontogeny of gaze following in chimpanzees, Pan troglodytes, and rhesus macaques, Macaca mulatta. Animal Behaviour, 61, 335-343. http://dx.doi.org/10 $.1006 /$ anbe. 2000.1598

Topál, J., Gergely, G., Erdôhegyi, A., Csibra, G., \& Miklósi, A. (2009). Differential sensitivity to human communication in dogs, wolves, and human infants. Science, 325, 1269-1272. http://dx.doi.org/10.1126/ science. 1176960

Topál, J., Kis, A., \& Oláh, K. (2014). Dogs' sensitivity to human ostensive cues: A unique adaptation? In J. Kaminski \& S. Marshall-Pescini (Eds.), The social dog: Behavior and cognition. New York, NY: Elsevier.

Turcsán, B., Szánthó, F., Miklósi, Á., \& Kubinyi, E. (2015). Fetching what the owner prefers? Dogs recognize disgust and happiness in human behaviour. Animal Cognition, 18, 83-94. http://dx.doi.org/10.1007/ s10071-014-0779-3

Vilà, C., Walker, C., Sundqvist, A. K., Flagstad, Ø., Andersone, Z., Casulli, A., ... Ellegren, H. (2003). Combined use of maternal, paternal and bi-parental genetic markers for the identification of wolf-dog hybrids. Heredity, 90, 17-24. http://dx.doi.org/10.1038/sj.hdy.6800175

Vilà, C., \& Wayne, R. K. (1999). Hybridization between wolves and dogs. Conservation Biology, 13, 195-198. http://dx.doi.org/10.1046/j.15231739.1999.97425.x
Virányi, Z., Gácsi, M., Kubinyi, E., Topál, J., Belényi, B., Ujfalussy, D., \& Miklósi, A. (2008). Comprehension of human pointing gestures in young human-reared wolves (Canis lupus) and dogs (Canis familiaris). Animal Cognition, 11, 373-387. http://dx.doi.org/10.1007/s10071-007-0127-y

Wallis, L. J., Range, F., Müller, C. A., Serisier, S., Huber, L., \& Virányi, Z. (2015). Training for eye contact modulates gaze following in dogs. Animal Behaviour, 106, 27-35. http://dx.doi.org/10.1016/j.anbehav 2015.04.020

Wilkinson, A., Mandl, I., Bugnyar, T., \& Huber, L. (2010). Gaze following in the red-footed tortoise (Geochelone carbonaria). Animal Cognition, 13, 765-769. http://dx.doi.org/10.1007/s10071-010-0320-2

Zimen, E. (1987). Ontogeny of approach and flight behaviour towards humans in wolves, poodles and wolf-poodle hybrids. In H. Frank (Ed.), Man and wolf: Advances, issues, and problems in captive wolf research. Dordrecht, the Netherlands: Dr. W. Junk Publishers.

Received March 10, 2016 Revision received April 13, 2016 Accepted April 16, 2016 